\title{
Artigos
}

\section{O cotidiano hospitalar de crianças com hospitalizações prolongadas: entre tramas dos cuidados com o corpo e as mediações possíveis}

The hospital routine of children with prolonged hospitalizations: between body-care and possible mediations (abstract: p. 15)

El cotidiano hospitalario de niños con hospitalizaciones prolongadas: entre tramas de los cuidados con el cuerpo y las mediaciones posibles (resumen: p. 15)

\author{
Mariana Pereira Simonato(a) \\ <mariana.simonato@inca.gov.br> \\ Rosa Maria de Araujo Mitre ${ }^{(b)}$ \\ <rmitre@gmail.com>
}

Sandra Maria Galheigo ${ }^{(\mathrm{c})}$

<sandramg@usp.br> (D)

\author{
(a) Seção de Oncologia Pediátrica, \\ Instituto Nacional de Câncer José \\ Alencar Gomes da Silva (INCA). \\ Praça da Cruz Vermelha, 23, Centro. \\ Rio de Janeiro, RJ, Brasil. 20230-130. \\ (b) Programa Saúde e Brincar, Instituto \\ Nacional de Saúde da Mulher, da \\ Criança e do Adolescente (IFF/ \\ Fiocruz). Rio de Janeiro, RJ, Brasil. \\ (c) Departamento de Fisioterapia, \\ Fonoaudiologia e Terapia \\ Ocupacional, Faculdade de Medicina, \\ Universidade de São Paulo (USP). \\ São Paulo, SP, Brasil.
}

Esta pesquisa de cunho etnográfico buscou refletir sobre o cotidiano de crianças com condições crônicas e complexas (CCC) com hospitalizações prolongadas. Foram realizadas: coleta de dados em prontuário, observações participantes do cotidiano hospitalar, e entrevistas com as mães de crianças internadas em duas unidades pediátricas. Os principais resultados mostraram que o cotidiano desses sujeitos era engendrado numa íntima relação do corpo com o ambiente e a importância da mediação das mães e dos profissionais de saúde nesse cenário. Como considerações, discute-se sobre as necessidades de saúde das crianças com CCC, que não contemplam apenas medicamentos e técnicas. É fundamental entender que o hospital constitui um espaço de vida cotidiana para essa população, o que implica a valorização da inclusão das mães e a oferta de espaços e atividades que possam favorecer o dia a dia dessas crianças.

Palavras-chave: Doença crônica. Processo saúde-doença. Criança hospitalizada. Assistência hospitalar. Terapia Ocupacional 


\section{Introdução}

O incremento no acesso às tecnologias de alta complexidade em saúde, bem como o aumento dos recursos para a detecção e intervenção precoces na saúde maternoinfantil permitem a ampliação da sobrevida de crianças pré-termos extremas, com malformaçôes congênitas e/ou adoecimento grave, aqui referidas como crianças com condiçôes crônicas e complexas em saúde (CCC) ${ }^{1}$.

Este grupo de crianças é identificado como aquele que, além de apresentar maior risco de condição crônica permanente, também precisa, com mais frequência e intensidade, dos serviços de saúde ${ }^{2}$. Mais frágeis do ponto de vista clínico, as crianças com CCC fazem parte de novo segmento que se mostra desafiador às políticas de saúde por demandarem alto nível de cuidado ${ }^{3}$ o que impacta sua família, rede social, equipe de cuidados e rede de atenção. Em termos de limitações funcionais, muitas destas crianças necessitam de alguma tecnologia para sobreviver. Seu tratamento usualmente requer: hospitalizações frequentes e/ou prolongadas, múltiplas intervenções e procedimentos, além da utilização contínua de serviços de saúde especializados.

Estudo realizado por Gomes et al. ${ }^{1}$, a partir de registros de internaçôes pediátricas em um hospital de referência para a saúde da criança, constatou que $84,2 \%$ das internações haviam sido de crianças e adolescentes com CCC, sendo a maioria com menos de um ano de idade. Esses dados mostram que, nesse segmento, encontram-se crianças que têm sua sobrevivência tornada possível à custa de hospitalizações no início de suas vidas.

Consideramos, neste estudo, período inicial de vida a fase de 0 a 24 meses, na qual a criança explora intensamente o ambiente a sua volta e depende em grande parte da mediação do adulto, na maioria das vezes a mãe, para conhecer o mundo a sua volta bem como para dar-lhe suporte afetivo.

Comumente, uma criança nasce no hospital e após alguns dias recebe alta para casa, onde é apresentada ao seu círculo familiar e ao novo ambiente. Durante os primeiros meses, sobretudo, explora intensamente este espaço, os objetos e as relações com as pessoas. Quando essa criança permanece hospitalizada, seu desenvolvimento é influenciado por diversos elementos da cultura hospitalar, por meio da exploração e relação com o espaço, objetos e atores deste território, pois é nele que habita.

Para Moreira ${ }^{4}$, quando o adoecimento crônico faz parte da vida desde o nascimento ou de seu período inicial, não há um momento de preexistência ao adoecimento. Nestes casos, ele é uma experiência constitutiva do sujeito e gera circuitos de sociabilidade, amizade, temas, objetos e repertórios de vida que dialogam com o viver adoecido cronicamente, compondo, assim, o processo de desenvolvimento. Ao apropriar-se de si e do mundo a sua volta, a criança também se apropria das atividades cotidianas neste espaço e dos gestos que as compóem. Estas atividades, aparentemente comuns, rotineiras, elementares, formam os fundamentos dos modos de viver humano. A vida segue assim, composta por esses gestos ínfimos e elementares que viabilizam o viver cotidianos.

A existência deste grupo de crianças com CCC, que cresce ao longo dos anos, impóe o desafio, aos pesquisadores e aos profissionais da assistência, de produzir conhecimentos que instrumentalizem as práticas em saúde, e auxiliem na reflexão crítica e construção de um cuidado de qualidade. Esse estudo tem como objetivo 
refletir sobre o cotidiano de crianças com CCC que passam longos períodos hospitalizadas na fase inicial da vida.

\section{Método}

Foi feito um estudo qualitativo utilizando a perspectiva etnográfica. A etnografia se caracteriza por uma descrição densa da experiência de imersão total na sociedade em questão $\mathrm{o}^{6,7}$. Acreditamos que, por meio dela, conseguimos entrar em contato com as formas de apropriação do ambiente hospitalar, geralmente sutis, pelas crianças com CCC que passaram os primeiros anos de vida hospitalizadas.

Ao falarmos da abordagem qualitativa e, em particular, da perspectiva etnográfica, estamos falando de experiências humanas, do encontro entre pesquisador e pesquisado ${ }^{7}$. As questóes que surgiram desse encontro no campo de pesquisa ocorreram por meio da observação participante com registros em diários de campo, e entrevistas narrativas com os acompanhantes, sobre: o cotidiano dessas crianças, suas rotinas, redes de sociabilidade, sua apropriação do ambiente hospitalar, suas relaçóes durante a internação e as mediaçóes ocorridas nesse espaço.

O campo do estudo foram: duas unidades de internação pediátricas, uma enfermaria e uma unidade semi-intensiva, de um instituto referência para o tratamento de CCC de saúde na infância e adolescência. Os sujeitos foram crianças com CCC, internadas há, pelo menos, noventa dias consecutivos e com admissão anterior a um ano de vida, e seus acompanhantes. O critério de inclusão para os acompanhantes foi conhecer e participar do cotidiano da criança durante a hospitalização, estando presentes no hospital ao menos dois dias da semana de forma regular. Não foram adotados critérios de exclusão.

Como a pesquisa qualitativa não se baseia em critério numérico para garantir sua representatividade ${ }^{8}$, a amostragem suficiente é aquela que possibilita abranger a totalidade do problema investigado em suas múltiplas dimensões. Assim, participaram todas as crianças, atendendo os critérios de inclusão, que estavam nas enfermarias no período do estudo, além de seus respectivos acompanhantes. Foi também realizado um levantamento de dados nos prontuários das crianças participantes da pesquisa, adaptado do estudo de Davies et al. ${ }^{9}$. Esses dados foram usados para traçar o perfil das crianças, como: município de origem, tempo de internação, diagnóstico, tecnologias usadas para suporte de vida, estomias, dentre outros.

A observação participante ocorreu entre os meses de junho e setembro de 2016, e as entrevistas com os acompanhantes aconteceram entre setembro e novembro do mesmo ano. Os nomes usados são fictícios para preservar a identidade dos sujeitos do estudo.

A análise dos dados foi conduzida pelo referencial da Análise de Conteúdo na modalidade Temática. Os registros dos diários de campo e os dados das entrevistas foram analisados separadamente e, posteriormente, discutidas possíveis correlaçóes ou peculiaridades entre eles. A interpretação dos dados obtidos na pesquisa de campo foi feita à luz do referencial teórico aqui exposto.

Esta pesquisa foi registrada e aprovada no CEP com o número CAAE: 55655116.6.0000.5269. 


\section{Resultados}

\section{Entrada no campo e a construção dos dados}

A entrada no campo ocorreu após conversas com algumas pessoas-chave nas duas unidades (enfermeiras diaristas e chefes, médicos, residentes médicos). Esta aproximação inicial facilitou a coleta de dados ao equacionar dúvidas sobre as questóes específicas de cada unidade.

Embora, no convite de entrevista às mães, fosse sugerida uma sala, algumas, para não se afastarem dos filhos, preferiram ser entrevistadas no próprio quarto ou no hall da enfermaria, o que foi aceito mesmo sabendo-se que não eram as condições ideais de entrevista. Arranjos foram feitos para que se preservasse o máximo possível o conteúdo dos relatos. Não houve qualquer recusa das mães à participação, ainda que isso possa estar relacionado à cultura de um hospital de ensino e pesquisa, onde a condição de vulnerabilidade que a própria hospitalização causa nessas mulheres pode fazer com que, muitas vezes, aceitem participar de uma pesquisa por acreditarem que, assim, seus filhos serão melhor cuidados, ou que é uma obrigação, já que seus filhos estão internados naquela instituição. Além disto, a posição que a pesquisadora ocupava em relação às mães - mais próxima de profissional da equipe - também pode ter influenciado.

\section{Caracterização do Campo}

A pesquisa foi realizada em um hospital de ensino e pesquisa, como dito anteriormente, que possui quarenta leitos de pediatria e cinco unidades de internação pediátrica. A unidade semi-intensiva caracteriza-se por receber pacientes em monitoramento contínuo por risco de apresentarem complicaçóes nas funçóes vitais e necessidade de procedimentos. Já a enfermaria de pediatria é a unidade de internação com crianças mais estáveis, mesmo se dependentes de tecnologia, sem necessidade de observação contínua e rigorosa da equipe.

Nas duas unidades, a presença do acompanhante era garantida e, apesar de grandes diferenças, elas apresentavam aspectos em comum: o leito como único espaço disponível para as crianças internadas permanecerem e a inexistência de solários, salas de convivência, brinquedotecas, espaços comuns ou abertos.

Outro ponto comum era a disposição das janelas, portas e iluminação. As janelas na enfermaria não podiam ser abertas nem possibilitavam ver o exterior pela altura, oferecendo apenas claridade. Na unidade semi-intensiva, havia uma janela que estava coberta por um filme escuro, impedindo, inclusive, a claridade do meio externo. Cada unidade tinha apenas uma porta dupla de entrada. No interior, portas separavam os espaços onde ficavam os leitos dos espaços reservados para a equipe. A iluminação, acesa quase o dia todo, era artificial, com luzes brancas.

A enfermaria, com 18 leitos, tinha um perfil de internação composto, em sua maioria, por crianças e adolescentes com CCC. Os leitos eram divididos em boxes separados por uma divisória de acrílico, permitindo à criança enxergar a criança do boxe ao lado. Nesse cenário, viviam crianças com agudização do quadro clínico, em investigação diagnóstica e aguardando alta com home care, processo que podia 
demorar meses ou até mesmo anos. Diferentemente de outras enfermarias pediátricas, muitas crianças dependiam de ventilação mecânica ou de alguma outra tecnologia.

A unidade semi-intensiva, com cinco leitos, abrigava crianças dependentes de ventilação mecânica invasiva e que tinham um estado clínico mais grave, necessitando de maior monitoramento da equipe de saúde. As crianças internadas nessa unidade, em sua grande maioria, permaneciam muito tempo até receberam alta para a enfermaria.

Durante o período de coleta de dados, todos os leitos estavam ocupados. Eles eram divididos por cortinas que, de modo geral, permaneciam abertas. Como era uma unidade pequena, as crianças, bem como os profissionais, conseguiam ver todo o espaço.

Importante destacar que o espaço físico diferenciado - bem menor na unidade semi-intensiva - e a relação entre o número de profissionais de saúde, em especial enfermagem, por paciente - bem maior na unidade semi-intensiva -, imprimiam uma dinâmica diferenciada entre as unidades.

\section{Perfil das crianças}

Participaram da pesquisa cinco crianças, sendo quatro do sexo masculino e uma do feminino; duas nascidas na instituição onde a pesquisa foi realizada e três transferidas por mandado judicial. Destas, duas eram da região metropolitana do Rio de Janeiro e uma do interior do estado (Tabela 1).

Quatro crianças aguardavam a decisão do pedido de home care. Três crianças haviam sido admitidas antes de um dia de vida, e duas, antes de seis meses de idade. A média de dias internados era de 795 dias, o que evidencia que crianças com CCC com hospitalizaçóes prolongadas se internam muito cedo e permanecem no hospital durante anos até a alta hospitalar (Tabela 1).

A judicialização, questão recorrente na vida das CCC, aconteceu para entrar ou sair do hospital e tem duas faces. Uma é o crescimento desordenado das açôes judiciais nos últimos anos, causando grande impacto à gestão do SUS por impor gastos inesperados aos poderes municipal, estadual e federal. A outra é por ser um importante sinalizador das necessidades individuais e coletivas de saúde ${ }^{10}$.

Todas as crianças eram traqueostomizadas; quatro dependiam de ventilação mecânica não invasiva e uma de ventilação mecânica invasiva. Três haviam sido internadas por quadro respiratório e quatro tinham diagnóstico de doença pulmonar crônica. Todas passaram por algum tipo de cirurgia e três precisaram de terapia intensiva (Tabela 2).

Tais achados parecem estar relacionados ao avanço tecnológico da medicina e estão relacionados com o acesso aos serviços de alta complexidade bem como à dependência dessas crianças às tecnologias de suporte à vida. 
Tabela 1. Caracterização das crianças

\begin{tabular}{|c|c|c|c|c|c|c|c|}
\hline Sujeito & Idade & Sexo & $\begin{array}{l}\text { Idade de } \\
\text { admissão }\end{array}$ & Motivo da admissão & Município & $\begin{array}{l}\text { Unidade de } \\
\text { internação }\end{array}$ & Mãe \\
\hline Rafael & 3 & M & Ao nascer & Prematuridade & Seropédica & UPI & Esther \\
\hline Miguel & 2 & M & Ao nascer & Prematuridade & Friburgo & UI e UPI & Isabel \\
\hline Daniel & 3 & M & Três meses & Quadro respiratório & Rio de Janeiro & UPI & Gabriela \\
\hline Ísis & 2 & $\mathrm{~F}$ & Ao nascer & $\begin{array}{l}\text { Má-formação congênita } \\
\text { e prematuridade }\end{array}$ & Queimados & UI & Eloá \\
\hline Matheus & 3 & M & Cinco meses & Quadro respiratório & Rio de Janeiro & $\mathrm{UI}$ & Cássia \\
\hline
\end{tabular}

Tabela 2. Características clínicas das crianças

\begin{tabular}{|c|c|c|}
\hline Características & Discriminação & Total \\
\hline \multirow[t]{2}{*}{ Pacientes } & Sexo masculino & 4 \\
\hline & Sexo feminino & 1 \\
\hline \multirow[t]{2}{*}{ Idade de admissão } & $<1$ dia & 3 \\
\hline & $<1$ dia a 6 meses & 2 \\
\hline \multirow[t]{3}{*}{ Motivo da admissão } & Quadro respiratório & 3 \\
\hline & Má-formação congênita & 1 \\
\hline & Prematuridade & 2 \\
\hline \multirow[t]{5}{*}{ Condição Clínica } & Doença Pulmonar Crônica & 4 \\
\hline & Cardiopatia & 1 \\
\hline & Malformações congênitas & 3 \\
\hline & ECNP & 1 \\
\hline & Microcefalia & 1 \\
\hline \multirow{2}{*}{$\begin{array}{l}\text { Necessidade de Terapia } \\
\text { Intensiva }\end{array}$} & Sim & 3 \\
\hline & Não & 2 \\
\hline \multirow[t]{2}{*}{ Cirurgia } & Sim & 5 \\
\hline & Não & 0 \\
\hline \multirow[t]{2}{*}{ Traqueostomia } & Sim & 5 \\
\hline & Não & 0 \\
\hline \multirow[t]{2}{*}{ Gastrostomia } & $\operatorname{Sim}$ & 5 \\
\hline & Não & 0 \\
\hline \multirow[t]{2}{*}{ Dependente de VeM } & Invasiva & 1 \\
\hline & Não invasiva & 4 \\
\hline \multirow[t]{2}{*}{ Aguardando Home Care } & Sim & 4 \\
\hline & Não & 1 \\
\hline
\end{tabular}

\section{A vida por entre as tramas dos cuidados com o corpo}

Em termos de rotina, o período da manhã era marcado pelos cuidados e atendimentos. À tarde, a movimentação diminuía nas duas unidades e havia a entrada de um programa interdisciplinar institucional que promovia: o brincar, atividades de leitura por voluntários, visitas, momentos de descanso e maior privacidade entre mãe e filho. Na unidade semi-intensiva havia o horário da soneca, período de uma hora com as luzes desligadas quando só procedimentos essenciais aconteciam. Ao final da tarde e anoitecer, os procedimentos e a movimentação nas duas unidades diminuíam, ficando apenas os profissionais plantonistas. Nesse horário, na enfermaria, podia-se ver a movimentação das mães nos boxes de outras crianças.

As crianças tinham uma rotina de cuidados intensa, independentemente da unidade em que estavam internadas. $O$ cotidiano na hospitalização era composto por diversas atividades, em sua maioria ligada aos cuidados em saúde. Eram elas: cuidados de higiene, cuidados com as estomias, alimentação, administração de medicamentos, 
coleta de material para exames, atendimentos clínicos dos diversos profissionais de saúde, brincar, descansar e dormir.

Estudar o cotidiano da hospitalização remete à própria discussão do lugar e sentido que este ocupa na vida contemporânea. A vida cotidiana é heterogênea, no sentido das diferentes atividades que a compóem como em seu grau de importância e significado. O cotidiano é também hierárquico, uma vez que as atividades humanas ocupam um lugar de destaque a depender das estruturas econômico-sociais nos diferentes momentos históricos ${ }^{11}$. O cotidiano é estreitamente relacionado às histórias das pessoas e dos povos e, portanto, contingente do contexto. No universo hospitalar, as atividades ligadas aos cuidados em saúde tornam-se, hierarquicamente, a esfera mais importante deste cotidiano; muitas vezes, as demais demandas e interesses são colocadas em segundo plano, frente à importância da luta pela sobrevivência ${ }^{12}$.

Nas entrevistas, as mães se referiram ao cotidiano de seus filhos como "normal", tal qual o de qualquer criança, porém preenchidos por cuidados em saúde. Pareceu-nos que o fato de estas crianças viverem com CCC de saúde desde o nascimento, modificou o que é considerado "normalidade" para essas mulheres, fazendo com que não distingam a rotina de seus filhos da de qualquer criança, apesar de reconhecerem o excesso de atividades de cuidado produzidas no ambiente hospitalar.

"Ele consegue ter uma rotina, "dentro do possível, normal". Só "tem muitos atendimentos né, aí ele toma banho como qualquer outra criança," se alimenta, quando ele consegue ficar fora do Bipap a gente vai dar uma volta [...] Durante o dia ele fica vendo DVD [...] Tem os cuidados da rotina... Basicamente isso.” (Gabriela)

A importância dada aos cuidados de saúde, alimentação e higiene acaba por encobrir as demais atividades, sobretudo, as lúdicas e sociais, que seriam típicas de crianças na faixa etária dos 2-3 anos.

A construção do cotidiano no ambiente hospitalar, quando vivido desde o início da vida da criança, com seus gestos particulares, compunha a vida da criança. Com isto, a mãe passou também por uma transformação em seu cotidiano, onde novos gestos e ações foram aprendidos e passaram a engendrar sua vida e a de seu filho. Consequentemente, passaram a considerar a vivência hospitalar dentro de uma normalidade, pois representava seu cotidiano e a experiência que garantia a manutenção da vida do filho. A vida cotidiana se resumia, portanto, ao que era possível ser vivido naquele tempo e lugar. Como afirmam Marquetti e Kinoshita, diariamente, construímos e refinamos os processos de interação do corpo em seu meio, a coordenaçã̃o de ações e emoções com os outros, e transformamos, no tempo e espaço vividos, esse gestual cotidiano que, ao longo de nossa história, compóe a própria vida.

Nas duas unidades, o banho e os cuidados começavam cedo. Essa rotina demandava muito tempo, pois eram realizados: os cuidados de higiene, os cuidados com as estomias e a administração de medicamentos. Isso envolvia, por exemplo: trocar fralda, cortar unha, pentear cabelo, hidratar a pele, aspirar a traqueostomia e colocar medicamentos tópicos nas estomias. 
Essas atividades eram sempre realizadas no leito. Na enfermaria, quando a criança estava acompanhada, essas atividades eram realizadas pelas mães. A presença da mãe parecia flexibilizar e mediar essa rotina da hospitalização. Elas utilizavam objetos trazidos de casa (como banheiras) e administravam o horário do banho com as outras rotinas de atendimentos, como, por exemplo, dar banho à tarde porque, durante a manhã, o filho recebeu muitos atendimentos.

$\mathrm{Na}$ unidade semi-intensiva, o banho era realizado pelos técnicos de enfermagem. Eram utilizados sacos plásticos e, dentro, colocavam-se água, sabonete e algodão. Este último era passado úmido no corpo das crianças, as aspirações eram mais frequentes e os cuidados com as estomias demandavam mais tempo. Talvez porque fossem necessários cuidados complexos com os acessos, curativos e estomias, exigindo atenção por parte dos profissionais, geralmente, o banho era realizado em silêncio, ainda que alguns conversassem com as crianças. Do mesmo modo, quando as crianças tentavam brincar com seu corpo e com objetos que estavam ao seu lado, não havia, de modo geral, um encorajamento para a criança participar da atividade.

O cuidado é direcionado, muitas vezes, a um corpo que responde pouco: não se movimenta, fala ou reclama, não diz se está bom ou ruim. Porém, percebe-se que esse cuidado ao corpo se torna uma forma de interação entre mãe e filho e é carregado de afeto, existindo um cuidado em significar aquela experiência para a criança. $\mathrm{O}$ cuidar do filho parece ser uma atividade extremamente significativa, que viabiliza o viver cotidiano na hospitalização para essas mulheres.

Paez e Moreira ${ }^{13}$ discutem como o nascimento de uma criança com malformaçóes graves torna insuficiente as conhecidas normas familiares de cuidados com bebês, e como a interpretação das mães dos gestos, olhares e reaçôes está baseada no reconhecimento de uma intencionalidade por parte dos filhos, que é a garantia da condição humana em ação. Assim, corroborando com nossos resultados, apesar de ter um corpo cuja sobrevivência está condicionada à subversão das formas de estar no mundo (alimentação, respiração, excreção, o brincar, o relacionar-se), quando inserida em uma ordem de intencionalidade nas atividades cotidianas, a criança transpóe o patamar da passividade.

O momento do banho também era um dos poucos momentos em que a mãe estava em contato com seu filho sem a mediação dos profissionais de saúde. Talvez, esse momento, considerado banal na vida cotidiana, seja carregado de significados pela intimidade que proporciona para essa população. Fazer o ordinário, o corriqueiro, ganha outra conotação, torna-se processo de subjetivação para esses sujeitos.

Os cuidados com as estomias, sobretudo, pareciam ser dolorosos e desconfortáveis, o que mobilizava profissionais e mães a conversarem mais com as crianças. Nestas ocasiôes, percebia-se um cuidado particularizado, onde era possível observar a presença de afeto e a preocupação em deixar a criança tranquila após o procedimento. A expressão de dor da criança parecia provocar uma resposta diferenciada, criando espaço para que o procedimento fosse realizado valorizando a relação com a criança.

Podemos relacionar essas particularidades na realização das atividades cotidianas com o conceito de espontaneidade de Heller ${ }^{11}$. Para a autora, a espontaneidade é a tendência de toda e qualquer forma de atividade cotidiana, caracterizando tanto as motivaçóes particulares quanto as comuns de todo ser humano. Seria impossível a produção e reprodução da vida da sociedade humana se refletíssemos sobre o conteúdo 
de todas as nossas formas de atividade. Assim, parece-nos que os profissionais de saúde e as mães particularizavam as atividades dolorosas, mas faziam isso sem refletir o porquê.

\section{Da disciplinarização dos corpos à mediação profissional na produção de cuidado}

A submissão inconteste da criança aos cuidados e procedimentos diários em uma unidade hospitalar não costuma ser pauta para reflexão na rotina de cuidados dos profissionais de saúde. Tal atitude parece refletir a concepção de que a criança é um sujeito em desenvolvimento e, portanto, ainda sem capacidade de discernimento e decisão. Entretanto, se "a imaturidade das crianças é um fato biológico da vida (...) os modos nos quais essa imaturidade é entendida e significada é um fato da cultura" ${ }^{14}$ (p. 7). Na situação hospitalar ainda se acrescenta que este é um espaço em que está estabelecida uma hierarquia no que se refere às intervençóes e cuidados, onde a equipe tem o poder e a autorização, pelo conhecimento técnico, de agir sobre a criança, fato não apenas esperado, mas também consentido pelas mães.

Se tomarmos a ideia de Foucaul $\mathrm{t}^{15}$ sobre a disciplinarização do espaço hospitalar, temos a criança, muitas vezes, sendo objeto das intervençóes da equipe de saúde e não sendo chamada a ter um papel ativo em seu processo de cuidado. $\mathrm{O}$ cotidiano hospitalar construído por essas mães e crianças é regido por uma ordem externa, preestabelecida, e pouco leva em conta seus desejos e singularidades. As atividades mais banais, como os horários de acordar, dormir, comer ou cuidar de seus filhos são regidas pela equipe de saúde, que prioriza a rotina de procedimentos e cuidados técnicos ${ }^{16}$. As crianças que nascem e têm a experiência da hospitalização prolongada logo no início da vida não conhecem outra realidade.

Fica difícil falar em promoção da autonomia e da produção de um sujeito ativo no cuidado em saúde, uma vez que esta experiência não é vivida nem nas atividades mais banais.

O que também pode influenciar na passividade das crianças é o sentimento de fragilidade e vulnerabilidade que marcou o conceito de infância no século XVIII, ainda presente atualmente ${ }^{17}$. As crianças, poucas vezes, são convidadas a ter um papel ativo em seu cuidado, e isso parece ser mais desafiador num ambiente hospitalar e com crianças com tantas dependências.

Entretanto, se pensamos na produção de cuidado humanizado e integral, precisamos retomar a ideia trazida pela Política Nacional de Humanização que "busca instituir uma 'nova cultura de atendimento"” 18 (p. 9). Afinal, o cuidado é uma via de mão dupla, um processo intersubjetivo, onde profissionais, crianças e suas mães, dialogam.

As mediações são fundamentais no contexto de hospitalização da criança com CCC, à medida que convoca e demanda atenção às relaçôes e combinações que surgem a partir da interação com profissionais e familiares ${ }^{19}$. São estes que inserem e ajudam a criança a transpor as barreiras ambientais e da própria CCC nesse ambiente restrito e repleto de particularidades. As mediações ampliam a variedade e a riqueza das experiências e do brincar da criança, dando a ela suporte para superar as restriçóes e ajudando-lhe a ter uma atividade criativa sólida e se desenvolver ${ }^{20,21}$; podem 
favorecer a autonomia das mesmas ao reconhecerem as diferentes formas de contato e comunicação (olhar, toque, fala), e buscarem negociar e incluir verdadeiramente as crianças como sujeitos de seu tratamento ${ }^{19}$.

Sobre as mediações dos profissionais de saúde, percebeu-se que independiam da categoria, mas pareciam estar ligadas à sensibilidade e disponibilidade em identificar os sinais de cada criança. Vale ressaltar que estamos falando de crianças com CCC em saúde, dependentes de diversas tecnologias e, na maior parte das vezes, com dificuldades motoras, cognitivas e de linguagem verbal.

Acreditamos que isso esteja relacionado, também, com a construção dualista da biomedicina entre o corpo (material, mensurável, objetivo) e o humano (espiritual, social, psicológico). Nesse dualismo existe uma valoração e uma hierarquia em que o corpo ocupa o lugar de destaque. Bonet ${ }^{22}$ fala como desse dualismo nasceu a 'tensão estruturante’ da biomedicina - a qual afastou três totalidades: o médico, o doente e a relação entre eles, deslocando para o inconsciente os aspectos emocionais, pois não se encaixavam no discurso criado sobre o processo saúde-doença. Porém, no cotidiano de trabalho, esses aspectos são trazidos à tona e seria possível perceber o caráter ilusório dessa separação. Esse autor fala da categoria médica, mas acreditamos que isso possa ser generalizado para as outras profissóes da área da saúde, pois a biomedicina ainda é a base para a graduação na área da saúde.

Os profissionais de saúde que conseguiam incluir a sensibilidade no cuidado diário com as crianças com CCC e suas mães, provavelmente, não tinham consciência dessa tensão, nem mesmo que estariam valorizando o 'sentir' sobre o 'saber'. E os profissionais que não valorizavam o 'sentir' na sua prática diária, ou não o deixavam aparecer, estariam respondendo à tradição em que foram formados ${ }^{22}$.

Essa mediação, também ligada ao investimento afetivo dos profissionais na criança, pode tornar a rotina hospitalar menos sofrida e árida, tanto para a criança como para suas mães. Mesmo ações corriqueiras e consideradas banais para os profissionais, são importantes e valorizadas pelas mães. Uma das possibilidades de resgatar o lugar de sujeito de crianças em ambientes de internação permeados por tecnologias duras é por meio do olhar dos profissionais nos momentos de aproximação e cuidado, valorizando e significando os sinais mais sutis ${ }^{23}$.

Sobre isto, Marquetti e Kinoshita ${ }^{5}$ dizem que “(...) geralmente acredita-se o sentido da vida aos eventos importantes, celebraçôes e situações extraordinárias” (p. 219). Entretanto, esses eventos são apenas alguns pontos de suspensão do cotidiano e não têm significação, se não forem incluídos no conjunto de ações e emoções coordenadas do nosso presente, pois a vida acontece, diariamente, no cotidiano 5 .

O afeto colocado na prática diária era uma parte importante para a satisfação da mãe com o cuidado direcionado a seu filho. Quando o afeto estava presente na relação com o profissional, mesmo crianças gravemente comprometidas davam sinais de resposta, ainda que sutis, percebidos pelas mães.

"[...] o pessoal, por exemplo, da fisioterapia motora "pra elas ele tá entendendo tudo". Eu gosto de ver o trabalho delas com ele e eu acho que ele até dá uma boa resposta por conta disso. [...] "acho que você acaba passando pro paciente, você passa que você acredita nele”.” (Esther) 
A inclusão e valorização do afeto na prática diária dos profissionais favorece a mediação feita por eles e proporciona autonomia possível para essas crianças tão dependentes, que pouco a experimentam em seu cotidiano, além de produzir um acolhimento para suas mães. Assim, a promoção de ações que visem e reinventem a assistência valorizando o mundo subjetivo, das relações, caminha para a construção da autonomia desses sujeitos ${ }^{23}$.

\section{Exploração lúdica, comunicação e interação via mediação materna}

A mediação da mãe com a criança se dava no sentido de apresentar o universo da hospitalização para seus filhos e vice-versa. Elas apresentavam seus filhos de uma forma subjetiva aos profissionais, seus gostos, preferências e rotina. As crianças participantes da pesquisa apresentavam grandes prejuízos na linguagem verbal, seja pelo atraso no desenvolvimento causado pela hospitalização prolongada ou pela própria CCC. As mães desempenhavam papel importante, pois acabavam sendo a 'voz' de seus filhos ao traduzirem seus gestos, desejos e vontades em palavras. Entendiam suas expressóes e a comunicação não verbal, interpretando-as para os profissionais. A compreensão da expressão da criança, por parte da equipe, favorecia a promoção de sua autonomia e participação, mesmo que de modo tênue e limitado.

Perceber o que a criança queria dizer com seus gestos, suas expressóes, seu estado de alerta, seu sono longo, tornava aquela criança única naquele ambiente generalizador. A mediação parecia ser um recurso das mães que imprimia subjetividade no cuidado diário, nas açôes da equipe de saúde e no modo como a criança era percebida naquele ambiente.

Tal necessidade de apresentar a criança em sua singularidade parecia estar ligada ao longo período de internação. Eram crianças e mães que viviam no hospital e conviviam durante muito tempo com a equipe; habitavam esse espaço, que ganhava, então, conotação de casa:

"[...] isso pra mim é o que eu mais tava dando prioridade, que eles (profissionais) conhecessem ele, porque não tem a questão da fala né, e eu entendo todos os sinais que ele me passa, [...] sabe que eu entendo e que vou fazer com que as meninas (equipe de enfermagem) também consigam entender pra que ele tenha um dia tranquilo. Eu entendi que essa era uma necessidade dele, entendi que as pessoas precisavam entender, porque ele assim não tá internado há um mês e vai pra casa semana que vem, ele tá morando aqui há dois anos e sete meses.” (Gabriela)

Outra característica ligada ao tempo de internação era a apropriação, pelas crianças, da rotina da hospitalização e do reconhecimento dos diferentes profissionais. Sabiam identificar qual profissional examinava, fazia exercício, lia, brincava. Essa apropriação da criança com CCC do cotidiano hospitalar parece acontecer da mesma forma que acontece com outras crianças nos espaços cotidianos domésticos, pela experiência diária e repetição. Porém, como ela está crescendo e vivendo em um ambiente hospitalar, se apropria do cotidiano, objetos, pessoas e intervençôes presentes nele. Vai 
explorar e se apropriar dos fios, tubos, estomias e monitores ligados a seu corpo, assim como conhecer e reconhecer as diversas pessoas que fazem parte deste ambiente.

As crianças pareciam transpor as limitaçóes do espaço reservado a elas, o leito, e explorá-lo do modo possível, de forma intensa. Um exemplo eram as divisórias de acrílico, que eram um recurso para facilitar a observação da equipe de saúde, mas serviam para as crianças explorarem o espaço com a visão e enxergarem além de seu quarto. As crianças criavam laços com seus "vizinhos", se comunicavam com gestos e com o corpo pelas divisórias. Parecia uma forma de prolongar a presença de quem se desejava, de tocar com os olhos e alcançar as pessoas da forma que era possível, naquele momento e espaço. Por vezes, brincavam pelas divisórias, interagiam.

A inserção do brincar no cotidiano dessas crianças, além de reafirmar que elas são sujeitos de direito, transformava o espaço e ampliava as possibilidades de exploração e experiências. Por meio da brincadeira e do brinquedo, a criança começa a agir independentemente daquilo que vê $\hat{e}^{21} \mathrm{e}$ isso é essencial para a criança com CCC em um contexto de hospitalização prolongada, no qual passa o período inicial do desenvolvimento com todas as restriçóes do ambiente hospitalar.

O brincar e o cuidado diário também apareceram como uma forma de aproximação da vida cotidiana em casa, ligados à "normalidade", ao que é conhecido e esperado. O brincar e o protagonismo da mãe nos cuidados diários dos filhos podem ajudar a qualificar o cuidado subjetivamente.

"Eu tento brincar bastante com meu filho [...] cuido do meu filho, é o mais próximo de casa que eu consigo chegar.” (Isabel)

Durante as brincadeiras e nos momentos dos cuidados, as crianças brincavam com seu corpo, com as tecnologias ligadas a ele e materiais disponíveis ao seu alcance. O corpo da criança com CCC muitas vezes é vinculado a diversas tecnologias de saúde: bipap, bomba infusora, traqueostomia, gastrostomia, tubos, entre outras. Quando a criança vivencia esse tipo de experiência desde seu início de vida, constrói sua experiência cotidiana de vida com esse aparato. Para ela, esta é sua normalidade, a sua maneira de existir. A exploração, a constituição de gestos e a brincadeira com os objetos hospitalares acontecem de forma espontânea como qualquer outro processo de exploração infantil.

Moreira ${ }^{4}$ fala que, nas crianças e jovens com doenças crônicas desde o nascimento, os sintomas e as necessidades geradas pela doença participam do processo de criação de identidade. Assim, o senso de normalidade e biografia é estabelecido incorporando a relação com a doença. A autora destaca o conceito de normalidade de Canguilhem que permite reconhecer a necessidade vital de crescer e se desenvolver que impulsiona as crianças a incorporarem aquilo que as constitui desde o nascimento - no caso, a doença crônica, seus sintomas e os objetos que fazem parte de sua vida -, marcando o cotidiano e as rotinas. 


\section{Considerações finais}

Dentro do cotidiano hospitalar de crianças com CCC com hospitalizações prolongadas, os cuidados em saúde assumiram o papel mais importante e estiveram ligados intimamente com sua sobrevivência. Este cotidiano, vivido também pelas mães que acompanham seus filhos, foi engendrado por gestos, açôes e objetos hospitalares, bem como pela própria condição crônica da criança, numa íntima relação do corpo com o ambiente. Estas crianças e suas mães construíram o cotidiano possível de ser vivido neste tempo e espaço, o qual garante um senso de normalidade para ambos. $\mathrm{O}$ cuidar e o brincar com o filho ganham uma conotação importante, pois se tornaram processos de subjetivação para essas crianças.

A mediação das mães e dos profissionais de saúde foi fundamental, pois por meio dela as crianças conseguiram transpor barreiras e se inseriram de forma particular nesse cotidiano. A mediação da mãe, que aparece como a voz dessas crianças, e a mediação do profissional que valoriza além dos sintomas e sinais corporais, produziram um cuidado humanizado e integral, possibilitando o exercício de viver a vida em condiçóes que poderiam levar à invisibilidade social.

Os dados e as demandas descritas neste estudo, ainda que singulares e não passíveis de generalizaçôes, podem relacionar-se e produzir reverberações em outros sujeitos envolvidos na mesma problemática, inclusive para pesquisadores, gestores e governantes, buscando dar visibilidade para a construção de políticas públicas para esta população.

As necessidades de saúde das crianças com CCC não contemplam apenas medicamentos e técnicas, mas, também, o vínculo, a longitudinalidade do cuidado e o acolhimento. Devem incluir não somente a criança, mas, por direito e necessidade, suas mães, como mediadoras e intérpretes de suas dores, incômodos e necessidades.

\section{Contribuições das autoras}

Todas as autoras participaram ativamente de todas as etapas de elaboração do manuscrito.

\section{Direitos autorais}

Este artigo está licenciado sob a Licença Internacional Creative Commons 4.0, tipo BY (https://creativecommons.org/licenses/by/4.0/deed.pt_BR).

(cc)

\section{Referências}

1. Gomes R, Moreira MCN, Moura EC, Madureira A, Machado DC, Menezes LA, et al. Documento síntese para validação de recomendações de pesquisa: diagnósticos das condições crônicas em pediatria no INSMCA Fernandes Figueira: retrato da morbidade hospitalar e linhas de cuidados. Rio de Janeiro: Instituto Nacional de Saúde da Mulher, da Criança e do Adolescente Fernandes Figueira; 2015. 
2. McPherson MG, Arango P, Fox H, Lauver C, Mc-Manus M, Newachek PW, et al. A new definition of children with special health care needs. Pediatrics. 1998; 102(1):13741 .

3. Moreira MEL, Goldani MZ. A criança é o pai do homem: novos desafios para a área de saúde da criança. Cienc Saude Colet. 2010; 15(2):321-7.

4. Moreira MCN. E quando a doença crônica é das crianças e adolescentes? Contribuiçóes sobre o artesanato de pesquisas sob a perspectiva da sociologia $\mathrm{da}$ infância e juventude. In: Catellanos MEP, Trad LAB, Jorge MSB, Leitão IMTA, organizadores. Cronicidade: experiência de adoecimento e cuidado sob a ótica das Ciências Sociais. Fortaleza: EdUECE; 2015. p. 125-55.

5. Marquetti FC, Kinoshita RT. A ação como precursora do pensamento no humano. Cad Ter Ocup UFSCar. 2011; 19(2):215-28.

6. Geertz C. A interpretação das culturas. Rio de Janeiro: Livros Técnicos e Científicos Editora; 1989.

7. Laplantine F. Aprender antropologia. São Paulo: Brasiliense; 2000.

8. Minayo MCS. Pesquisa social: teoria, método e criatividade. 5a ed. Petrópolis: Vozes; 1996.

9. Davies D, Hartfield D, Wren T. Children who 'grow up' in hospital: inpatient stays of six months or longer. Paediatr Child Health. 2014; 19(10):533-6.

10. Gomes FFC, Cherchiglia ML, Machado CD, Santos VC, Acurcio FA, Andrade EIG. Acesso aos procedimentos de média e alta complexidade no Sistema Único de Saúde: uma questão de judicialização. Cad Saude Publica. 2014; 30(1):31-43.

11. Heller A. O cotidiano e a história. 8a ed. São Paulo: Paz e Terra; 2008.

12. Simonato MP. Sutilezas e tessituras do ambiente hospitalar: o cotidiano de uma enfermaria pediátrica de média e alta complexidade [monografia]. Rio de Janeiro: Instituto Nacional de Saúde da Mulher, da Criança e do Adolescente Fernandes Figueira, Fundação Oswaldo Cruz; 2015.

13. Paez A, Moreira MCN. Construções de maternidade: experiências de mães de crianças com síndrome do intestino curto. Physis. 2016; 26(3):1053-72.

14. Prout A, James A. A new paradigm for the sociology of childhood? Provenance, promise and problems. In: Prout A, James A, organizadores. Constructiong and reconstructing childhood. London: Falmer Press; 1990. p. 7-34.

15. Foucault M. O nascimento da clínica. 2a ed. Rio de Janeiro: Forense Universitária; 1980.

16. Angeli AA, Luvizaro NA, Galheigo SM. O cotidiano, o lúdico e as redes relacionais: a artesania do cuidar em terapia ocupacional no hospital. Interface (Botucatu). 2012; $16(40): 161-71$.

17. Ariès P. História social da criança e da família. 2a ed. Rio de Janeiro: LTC; 1981.

18. Deslandes S. Análise do discurso oficial sobre a humanização da assistência hospitalar. Cienc Saude Colet. 2004; 9(1):7-14.

19. Moreira MCN, Gomes R. O cuidado à criança hospitalizada: interaçóes simbólicas entre as dimensóes profissionais e leigas. Diversitates. 2015; 7(1):40-53.

20. Vygotsky LS. Imaginação e criatividade na infância. São Paulo: Martins Fontes; 2014.

21. Vygotsky LS. A formação social da mente. São Paulo: Martins Fontes; 2007. 
22. Bonet O. Saber e sentir: uma etnografia da aprendizagem da biomedicina. Rio de Janeiro: Fiocruz; 2004.

23. Duarte MCS, Moreira MCN. Autonomia e cuidado em terapia intensiva pediátrica: os paradoxos da prática. Interface (Botucatu). 2011; 15(38):687-700.

This ethnographic study reflected upon the experiences of prolonged hospitalization among children with chronic and complex conditions (CCC). Data was collected from the patients' medical records, participant observation, and interviews conducted with the parents of children hospitalized in two pediatric units. The findings reveal that the patients' daily lives were engendered by an intimate relationship between the body and environment and the importance of the mediation of parents and health professionals in this setting. A number of considerations are suggested, including the fact that the health needs of children with CCC extend beyond medication and techniques. It is vital to understand that the daily life of these children is played out temporarily in the hospital and therefore theses settings require the active presence of mothers and the provision of spaces and activities to optimize the daily lives of these children.

Keywords: Chronic disease. Health and disease process. Hospitalized child. Hospital care. Occupational therapy.

Este estudio de cuño etnográfico buscó reflexionar sobre el cotidiano de niños con condiciones crónicas y complejas (CCC) con hospitalizaciones prolongadas. Se realizaron colecta de datos en historial, observaciones participantes del cotidiano hospitalario y entrevistas con las madres de niños internados en dos unidades pediátricas. Los principales resultados mostraron que el cotidiano de esos sujetos se engendraba en una íntima relación del cuerpo con el ambiente y la importancia de la mediación de las madres y de los profesionales de la salud en ese escenario. Como consideraciones, se discute sobre las necesidades de salud de los niños con CCC que no incluyen tan solo medicamentos y técnicas. Es fundamental entender que el hospital se constituye como espacio de vida cotidiana para esta población, lo que implica la valorización de la inclusión de las madres y la oferta de espacios y actividades que puedan favorecer el el dia a dia de estos ninôs..

Palabras clave: Enfermedad crónica. Proceso salud enfermedad. Niño hospitalizado. Asistencia hospitalaria. Terapia Ocupacional. 